\title{
OJS

\section{VERDADES E FAKE NEWS: USO DA DINÂMICA DE COMUNICAÇÃO DO WHATSAPP NO ENSINO DE REGIÕES POLARES PARA O ENSINO SUPERIOR EM GEOGRAFIA}

\author{
Carina Petsch ${ }^{1}$, Luiz Felipe Velho ${ }^{2}$, Rafaela Mattos Costa $^{3}$, Katia Kellem da Rosa ${ }^{4}$
}

\begin{abstract}
IProfessora adjunta da Universidade Federal de Santa Maria (UFSM).E-mail: carinapetsch@gmail.com-ORCID iD: http://orcid.org/0000-0002-1079-0080;

${ }^{2}$ Professor do Instituto Federal de Ciência e Tecnologia do Rio Grande do Sul - Campus Porto Alegre. E-mail: lfvelho@gmail.com-ORCID iD: http://orcid.org/0000-0001-9543-7544;

${ }^{3}$ Discente de mestrado no Programa de Pós-graduação em Geografia da Universidade Federal do Rio Grande do Sul (UFRGS).E-mail: raffaellamattos@ hotmail.com-ORCID iD: http://orcid.org/0000-0003-0496-7377;

${ }^{4}$ Professa do Departamento de Geografia da Universidade Federal do Rio Grande do Sul (UFRGS). E-mail: katiakellem@gmail.com - ORCID iD: http://orcid.org/0000-0003-0977-9658.
\end{abstract}

Artigo recebido em 11/10/2019 e aceito em 20/04/2020

\begin{abstract}
RESUMO
O objetivo desta pesquisa é apresentar novas formas de abordar as mudanças climáticas e o ensino de regiões polares com alunos de graduação em Geografia através da discussão interdisciplinar, sistêmica e ainda da elaboração de material didático atrelado às novas tecnologias de informação e comunicação, como o WhatsApp. As mudanças climáticas podem ser consideradas um novo paradigma no ensino da geografia escolar e superior, e necessitam de novas metodologias para guiar o professor nessa tarefa. O primeiro momento foi reservado para a distribuição das notícias verdadeiras e falsas para os alunos. A segunda etapa consistiu em uma apresentação com informações e explicações sobre Antártica e mudanças climáticas, visando apoiar os alunos na avaliação das notícias distribuídas. A terceira etapa caracterizou-se pela apresentação, aos alunos, de materiais utilizados por pesquisadores, na Antártica. A atividade envolvendo WhatsApp, ao demonstrar a visão sistêmica de muitos alunos em relação às mudanças climáticas, revelou uma série de possibilidades de abordagem dos assuntos, atreladas não somente à (s) disciplina (s) de Climatologia. Ao tratar das mudanças climáticas nas disciplinas de Biogeografia, Geografia da População, Geografia Agrária, Geografia Cultural, Climatologia, Cartografia, Geomorfologia e Geografia Urbana, é possível aprofundar essas relações sistêmicas entre o ser humano e o meio. Sendo assim, o professor precisa de atualização constante, pois a quantidade e a diversidade de materiais científicos publicados são grandes, assim como a disseminação de fake news climáticas.
\end{abstract}

Palavras-chave: Ensino de geografia. Mudanças climáticas. TIC. 


\title{
TRUTHS AND FAKE NEWS: USING WHATSAPP'S COMMUNICATION DYNAMICS IN TEACHING POLAR REGIONS FOR HIGHER EDUCATION IN GEOGRAPHY
}

\begin{abstract}
The aim of this research is to present new ways of approaching Climate Change and teaching polar regions to undergraduate students in Geography through interdisciplinary discussion and the construction of courseware linked to new information and communication technologies, such as WhatsApp. The first step was set aside for news distribution to students. The second step consisted in a presentation with information and explanations on Antarctica and climate change, aiming to support students to answer true or false to the news. In the third step students could touch and wear some objects used by researchers in Antarctic fieldworks. The use of WhatsApp to demonstrate a systemic approach of climate change has revealed different possibilities to understand these subjects using knowledge from Climatology and other disciplines. By addressing climate change in the disciplines of biogeography, population geography, agrarian geography, cultural geography, climatology, cartography, geomorphology and urban geography, it is possible to deepen these systemic relations between the physical and the human. Therefore, the teacher needs constant updating, as the quantity and diversity of published scientific materials are large, as well as the spread of fake climate news.
\end{abstract}

Keywords: Climate change. Geography teaching. TIC.

\section{VERDADES Y NOTICIAS FALSAS: UTILIZAR LA DINÁMICA DE COMUNICACIÓN DE WHATSAPP EN LA ENSEÑANZA DE LAS REGIONES POLARES PARA LA EDUCACIÓN SUPERIOR EN GEOGRAFÍA}

\begin{abstract}
RESÚMEN
El objetivo de esta investigación es presentar nuevas formas de abordar el cambio climático y la docencia de las regiones polares con estudiantes de pregrado en Geografía a través de la discusión interdisciplinaria, sistémica y también la elaboración de material didáctico vinculado a las nuevas tecnologías de la información y la comunicación, como WhatsApp. . El cambio climático puede considerarse un nuevo paradigma en la enseñanza de la escuela y la geografía superior, y se necesitan nuevas metodologías para orientar al docente en esta tarea. El primer momento estuvo reservado para la distribución de noticias verdaderas y falsas a los estudiantes. La segunda etapa consistió en una presentación con información y explicaciones sobre la Antártida y el cambio climático, con el objetivo de apoyar a los estudiantes en la evaluación de las noticias distribuidas. La tercera etapa se caracterizó por la presentación a estudiantes de materiales utilizados por investigadores en la Antártida. La actividad de WhatsApp, al demostrar la visión sistémica de muchos estudiantes en relación al cambio climático, reveló una serie de posibilidades para abordar temas, vinculados no solo a la (s) asignatura (s) de Climatología. Al abordar el cambio climático en las disciplinas de Biogeografía, Geografía Poblacional, Geografía Agraria, Geografía Cultural, Climatología, Cartografía, Geomorfología y Geografía Urbana, es posible profundizar estas relaciones sistémicas entre los humanos y el medio ambiente. Por tanto, el profesor necesita una actualización constante, ya que la cantidad y diversidad de materiales científicos publicados son grandes, así como la difusión de noticias climáticas falsas.
\end{abstract}

Palabras clave: Enseñanza de la geografía. Cambios climáticos. TIC. 


\section{INTRODUÇÃO}

Há alguns anos, a principal fonte de informação da sociedade eram as televisões e os rádios. Moran (2012) destaca que o jovem tinha, na sua maioria, uma educação com influência da televisão, sendo considerada uma fonte de informação e de conhecimento sobre outros lugares. Contudo, houve uma modificação nesse cenário. Os alunos, não são mais grandes telespectadores, mas utilizam frequentemente WhatsApp, Netflix, Facebook, Instagram, Tik Tok e Twitter. Isso ocorre porque, em sua maioria, os jovens têm os smarthphones como companheiros inseparáveis em seu cotidiano, inclusive na sala de aula. Essa inseparabilidade, ou dependência, é percebida por professores, alunos e pais, pois é comum os jovens direcionarem a atenção para as notificações do WhatsApp, que aparecem na tela do celular.

Assim como nas décadas passadas entendia-se que a televisão fazia parte da construção das percepções dos indivíduos, hoje entende-se que os aplicativos de mensagens instantâneas e as redes sociais atingem a formação dos sujeitos tanto quanto a sala de aula, e que é necessário que o ambiente acadêmico compreenda essa nova significação e interpretação de situações da atualidade, promovendo uma nova postura de educação crítica para os jovens em formação de nível superior. Portanto, torna-se cada vez mais importante a investigação sobre o uso desses aplicativos como ferramentas de disseminação de conteúdo e de espaço para o exercício da criticidade com os materiais acessados.

Ao passo que os aplicativos de mensagens instantâneas ampliam a quantidade de informação que os jovens recebem, os currículos de graduação não são atualizados com a mesma velocidade e, em alguns casos, percebe-se que o licenciando não está preparado para lidar com temáticas emergentes em sala de aula. Um exemplo é o tema "mudanças climáticas e regiões polares", ainda pouco discutido nas salas de aula e com pouco material atualizado, apresentando dados recentes. Bertotti et al. (2013), por exemplo, ao observarem e analisarem diversos livros didáticos de Geografia, constataram que muito pouco se apresenta sobre conteúdos relacionados à importância da Criosfera para a Terra e para o Brasil. Assim, sem uma preparação na formação do professor (currículo de graduação) e sem material didático de apoio para facilitar a abordagem de mudanças climáticas e de Geografia das regiões polares, há uma lacuna na formação dos futuros licenciados para atuarem em temas cada vez mais atuais, fundamentais para a formação de cidadãos com conhecimento para combater a propagação de notícias sem cunho científico. 
Ainda nesse sentido, o ensino das mudanças climáticas e da Antártica, num contexto de mudanças ambientais globais, e que também afetam o Brasil, constitui-se em paradigma que necessita de reflexões, especialmente no âmbito da Geografia escolar. Jacobi et al. (2011) aponta que, para o efetivo processo de ensino-aprendizagem, no que se refere às mudanças climáticas, é necessária a elaboração de materiais didáticos, especialmente no caso de abordagens sobre clima, correntes marítimas, composição da atmosfera, entre outros. Contudo, muitas questões ainda demandam discussão diante da alta complexidade do assunto "Mudanças climáticas e Antártica": quais estratégias podem ser adotadas para o ensino? É possível, em uma realidade onde o conhecimento acaba sendo fragmentado, estabelecer uma abordagem sistêmica do assunto? No contexto das fake News e da desvalorização da Ciência, como isso impacta no ensino de Mudanças Climáticas e Antártica? E, ainda, de que forma as mídias sociais podem ser aliadas ou vilãs nesse processo?

Logo, avaliar a dinâmica de disseminação de informações nos aplicativos de mensagens instantâneas é uma forma de trabalhar questões que estão sendo discutidas na sociedade utilizando uma estrutura de comunicação familiar aos jovens. Com isso, gera-se um campo fértil para o desenvolvimento de uma aprendizagem significativa, aliando a essência das novas tecnologias de informação e comunicação (TIC) às metodologias de ensino no ambiente acadêmico (ALMEIDA et al. 2010). Segundo Stürmer (2011), as TIC podem proporcionar, ao aluno, acesso a novos conhecimentos contidos na internet, além de permitir a leitura e interpretação de paisagens distantes de sua realidade, como a Antártica.

Tonetto e Tonini (2015) avaliam que há diferentes potencialidades para o uso das redes sociais on-line em sala de aula visando a construção de processos de aprendizagens significativas. As autoras destacam que as redes sociais representam a forma contemporânea dos jovens se comunicarem e interagirem em seu cotidiano e o processor pode concetar a sala de aula ao mundo contemporâneo. Oliveira e Tonini (2015) discutem que as redes sociais podem ser transformadas em ambientes virtuais de aprendizagem e permitem diversas dinâmicas e atividades em sala de aula.

Diante do exposto, o objetivo desta pesquisa é apresentar formas de abordar as mudanças climáticas e o ensino de regiões polares aos alunos de graduação em Geografia através da discussão interdisciplinar, utilizando-se material didático baseado no leiaute e na estrutura das novas TIC. Para tanto, uma oficina para alunos de Graduação em Geografia foi realizada, utilizando-se a estrutura de veiculação de notícias em uma simulação do aplicativo WhatsApp. 


\section{MATERIAIS E MÉTODOS}

Para melhor compreensão de todo o processo de realização da oficina, desde o seu planejamento até a análise dos resultados, foi construída a Tabela 1, onde são pormenorizadas as etapas de concepção, execução e avaliação. Este trabalho possui um caráter quali-quantitativo, relatando as percepções dos autores sobre a oficina realizada.

Tabela 1: Estruturação das etapas de concepção, execução e avaliação da oficina.

\begin{tabular}{|c|c|c|}
\hline Etapa & Objetivo & Atividades \\
\hline Concepção & Planejar a oficina & $\begin{array}{l}\text { Escolha da TIC a ser utilizada na oficina; } \\
\text { Distribuição da duração das atividades; } \\
\text { Construção dos materiais e da pauta de } \\
\text { discussões; } \\
\text { Escolha das notícias verdadeiras e falsas a serem } \\
\text { utilizadas. }\end{array}$ \\
\hline Execução & Realizar a oficina & $\begin{array}{l}\text { Organização do material de sensibilização; } \\
\text { Proposição de reflexão a respeito das notícias } \\
\text { distribuídas; } \\
\text { Discussão da pauta com os assuntos elencados; } \\
\text { Relaxamento e sensibilização com material } \\
\text { utilizado por pesquisadores. }\end{array}$ \\
\hline Avaliação & $\begin{array}{l}\text { Analisar as respostas, identificando } \\
\text { alinhamento com o processo } \\
\text { construído para a oficina }\end{array}$ & $\begin{array}{l}\text { Análise do conteúdo das respostas; } \\
\text { Análise das discussões em grupo; } \\
\text { Caracterização dos conteúdos e disciplinas mais } \\
\text { citadas nas respostas e discussões; } \\
\text { Identificação das principais disciplinas a serem } \\
\text { envolvidas em práticas interdisciplinares para o } \\
\text { ensino de mudanças climáticas. }\end{array}$ \\
\hline
\end{tabular}

Fonte: elaborado pelos autores, 2019. 


\section{CONCEPÇÃO}

Dada a popularização do uso do WhatsApp e todas as discussões atuais sobre a veiculação de fake news através de grupos criados nesta ferramenta de mensagens, optou-se pelo uso do leiaute deste aplicativo. Considerando que o público alvo é heterogêneo, pois nem todos os participantes têm acesso à internet e à smartphones com suporte ao aplicativo WhatsApp, e que poderia não ocorrer a anuência da totalidade dos alunos em fornecer seus números de telefone, optou-se por utilizar o leiaute impresso do aplicativo (Figura 1).

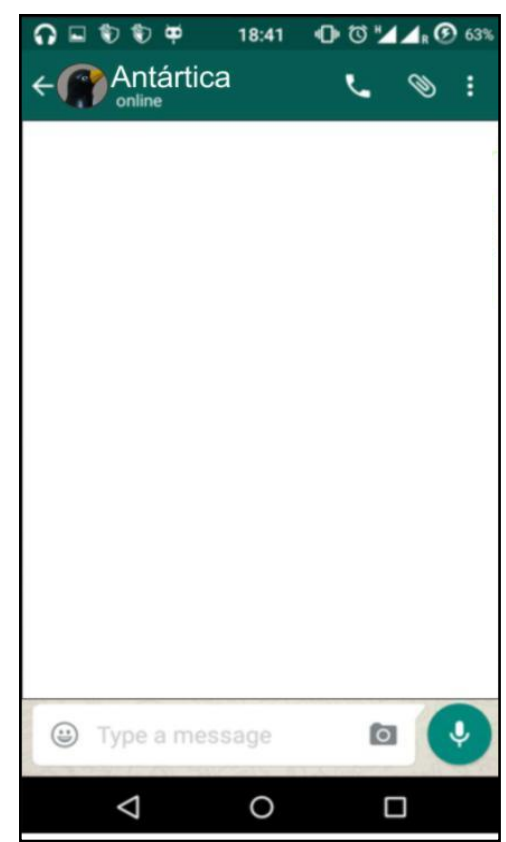

Figura 1. Representação de uma janela de visualização do aplicativo WhatsApp, utilizada como base para a disposição de notícias para os alunos. Fonte: Adaptado, pelos autores, de uma cópia de tela de telefone móvel. Fonte: acervo dos autores, 2019.

É importante ressaltar que o curso de Graduação em Geografia, alvo desta oficina, não tem nenhum componente curricular voltado diretamente para o estudo da Antártica ou das mudanças climáticas. Dada a falta de conhecimento prévio, por parte dos participantes da oficina, a oficina foi estruturada para ser realizada em três momentos, quais sejam: (i) distribuição de notícias; (ii) apresentação de material audiovisual; e (iii) apresentação de material de sensibilização.

Foram elencados, para discussão, os seguintes assuntos a respeito da Antártica: vestimentas, alimentação, turismo e acampamentos. Quanto às mudanças climáticas, optou-se por: aumento do nível do mar e efeitos sistêmicos na Terra. Algumas fotografias, de expedições antárticas e de outras 
regiões da Terra, como Alasca, região andina e Alpes europeus, foram selecionadas. O uso de fotografias, juntamente com as notícias, teve por objetivo estimular visualmente os alunos, promovendo maior percepção de diferentes ambientes (Figura 2).
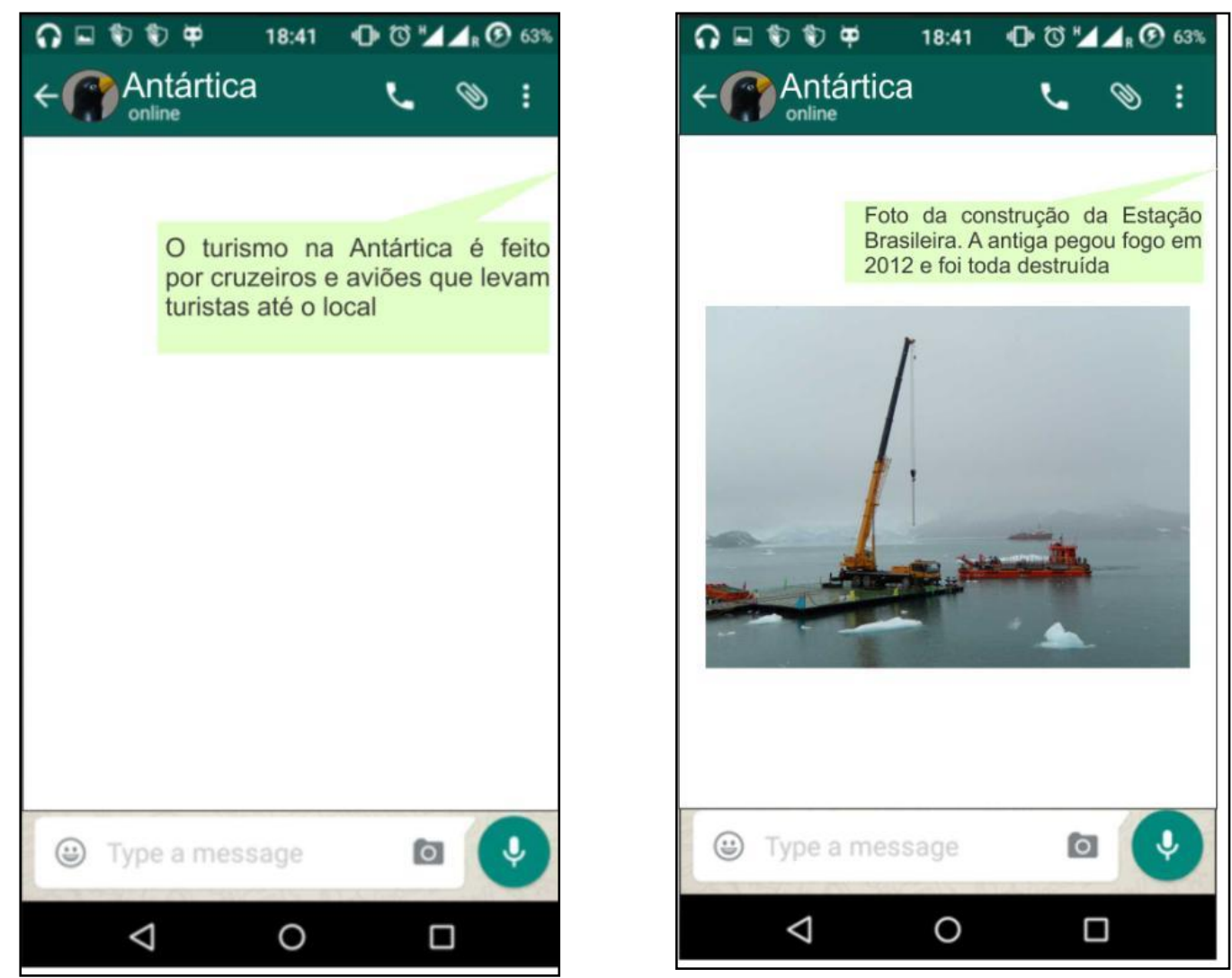

Figura 2: Informações dispostas como mensagens no grupo do WhatsApp fictício. Fonte: acervo dos autores, 2019.

\section{EXECUÇÃO}

Seguindo o planejamento descrito na seção anterior, a oficina foi realizada em três momentos distintos (Figura 3). A realização de cada momento é descrita a seguir. Antes do início da oficina, um espaço foi montado com os principais materiais utilizados por pesquisadores, em suas atividades de campo na Antártica. Assim, casacos, botas, luvas, gorros, sacos de dormir, entre outros objetos, ficaram expostos. Esse material foi utilizado no último momento da oficina. 


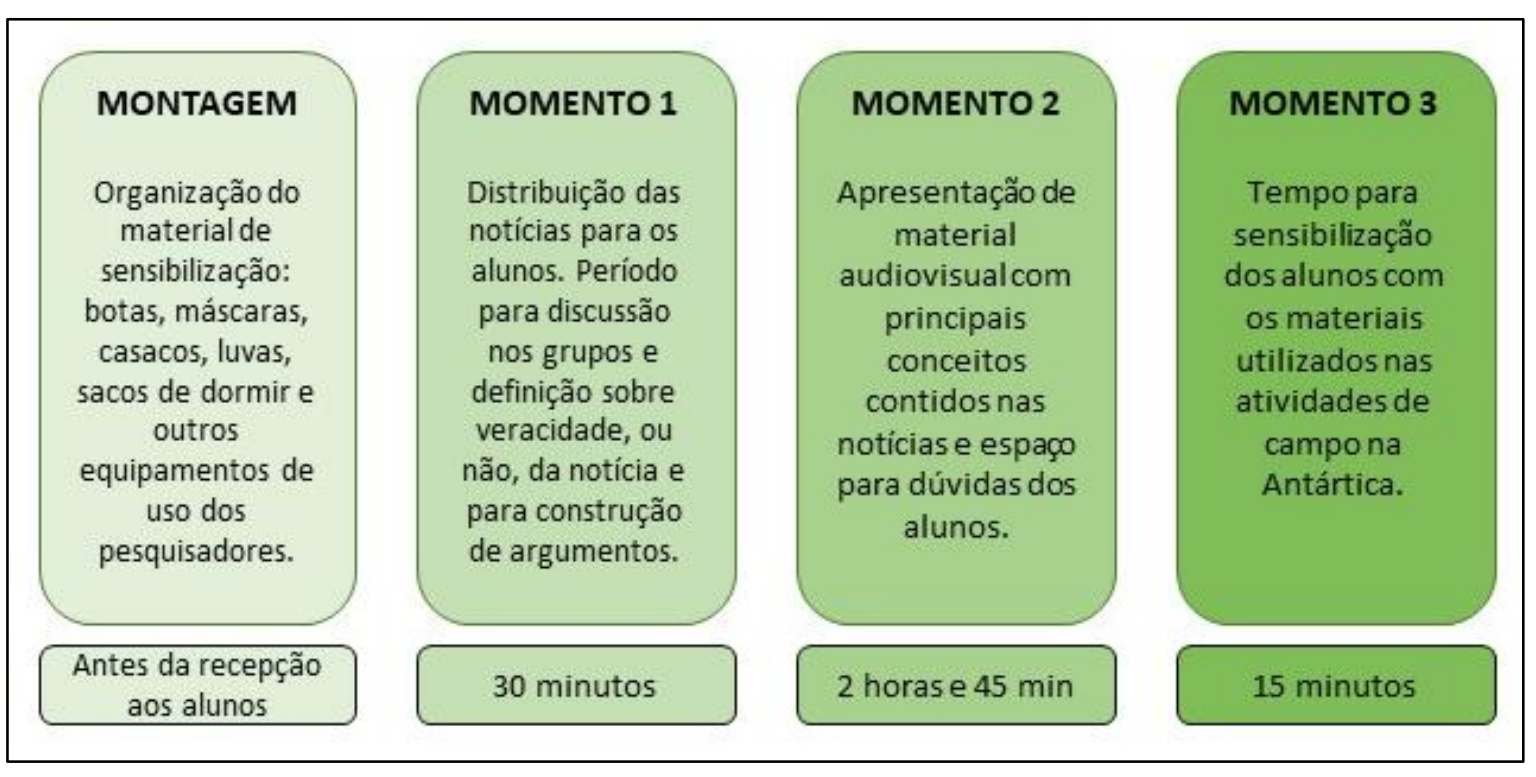

Figura 3: Distribuição das atividades e dos tempos durante a execução da oficina. Fonte: dados da pesquisa, 2019.

Após a chegada dos alunos, o primeiro momento da oficina, com trinta minutos de duração, foi reservado para a distribuição das notícias. No fictício “Grupo Antártica”, elaborado em um leiaute do WhatsApp (Figura 2), os alunos responderam se a notícia recebida é verdadeira ou falsa.

O segundo momento consistiu em uma apresentação, pelo ministrante da oficina, de vídeos e eslaides com informações e explicações sobre Antártica e mudanças climáticas, visando apoiar os alunos na avaliação das notícias distribuídas como verdadeiras ou falsas. Esta etapa durou duas horas e quarenta e cinco minutos. Neste período, o ministrante pôde responder aos questionamentos que, porventura, os alunos tenham elaborado durante o primeiro momento, e ainda estimulá-los a estabelecer relações entre as notícias distribuídas.

O último momento (terceiro) caracterizou-se pela apresentação, aos alunos, de materiais utilizados na Antártica, por pesquisadores. A duração proposta foi de quinze minutos. Objetivou-se que os alunos se aproximassem da realidade de um ser humano em um ambiente polar através da experimentação de material (objetos de trabalho e vestimentas), ampliando a percepção acerca do ambiente e dos sistemas que o compõe.

\section{AVALIAÇÃO}

A avaliação foi composta pela análise das respostas dadas para as notícias, bem como as discussões ocorridas durante a oficina. Essa análise baseia-se na identificação das principais perguntas e/ou termos utilizados, pelos alunos, para desenvolver sua argumentação a respeito dos 
temas propostos. Caso os alunos não tenham conectado as discussões com conteúdos de disciplinas específicas de seu currículo, essas informações foram anotadas para a construção de uma lista de disciplinas passíveis de integrar atividades interdisciplinares sobre Antártica e mudanças climáticas.

\section{RESULTADOS}

Sobre a concepção da oficina, todas as atividades previstas na Tabela 1 foram realizadas. Um total de quarenta participantes foi atingido pela atividade, sendo todos estudantes do primeiro ao quarto ano de Graduação em Geografia.

Em relação aos materiais elaborados, foram criadas 32 notícias diferentes, das quais se optou por colocar, na sua maioria (19 informações), dados científicos sobre a Antártica e Mudanças Climáticas. Em menor quantidade (13 notícias), foram inseridas algumas curiosidades sobre o continente antártico. Essa separação deu-se pelo fato de as curiosidades serem de conhecimento dos alunos apenas por meio de documentários ou filmes. Já os dados científicos, ainda que os discentes não tenham vivenciado aulas específicas sobre o assunto, poderiam ser deduzidas a partir dos conteúdos de diferentes disciplinas, provocando a mobilização de saberes e a criticidade na avaliação da notícia a partir de conjuntos teóricos. Todas as notícias foram relacionadas com os assuntos elencados na seção "concepção".

Acerca da execução da oficina, os períodos estipulados para cada etapa foram adequados e possíveis de serem aplicados ao grupo. Conforme planejado, os alunos receberam a informação apresentada no leiaute do WhatsApp, responderam a mensagem, e posteriormente leram para todos os participantes (Momento 1 - Figura 3), enquanto o ministrante passou a fazer perguntas, instigando e desafiando a todos os envolvidos, porém, sem apresentar a resposta. No Momento 2 (Figura 3), os alunos puderam acompanhar, juntamente com o ministrante, os materiais multimídia escolhidos para abordar as mudanças climáticas e Antártica, enquanto as perguntas feitas na primeira parte foram respondidas. A avaliação da oficina foi realizada com base nas anotações feitas pelo ministrante, dos Momentos 1 e 2, sobre os assuntos aos quais os alunos realizavam perguntas e, também, dos principais aspectos das respostas dadas pelos discentes. Além disso, foram avaliadas as respostas nos materiais impressos com as notícias.

Nessa avaliação, das anotações e das respostas dos alunos, alguns termos se repetiram. Esses temas recorrentes serão apresentados a seguir, em negrito. Um dos temas é o imediatismo e rapidez 
no degelo do continente antártico. O tema surgiu a partir da informação apresentada no WhatsApp: “em todas as partes da Antártica é possível observar derretimento do gelo".

Apesar de alguns alunos (menos de 15\%) dos participantes acreditarem que o derretimento será cada vez mais rápido, a maioria questionou o fato de a informação apresentar "toda Antártica". Os alunos entendem que o continente é dinâmico e possui uma massa de gelo considerável. Sendo assim, o comportamento do manto de gelo, diante das mudanças climáticas, não seria passível de desintegração. Os alunos apresentaram, dessa forma, um conhecimento sistêmico e climatológico apurado.

Foram apresentadas duas informações a respeito do relevo: uma fotografia mostrando áreas sem a presença de neve (no verão) e picos rochosos e uma informação sobre turismo em praias Antárticas. Essas informações suscitaram inúmeras observações acerca do modelado da superfície da Antártica. Na fotografia, mais de $85 \%$ dos alunos disseram que há, de fato, variações nas formas de relevo antártico, e que esse continente possui gelo cobrindo montanhas. Alguns alunos mencionaram que já haviam assistido vídeos, no YouTube, onde haviam observado montanhas na Antártica. Um fator interessante, quanto ao relevo, ocorreu na informação da praia. Cerca de $30 \%$ dos alunos citaram que não há praia na Antártica (Figura 2), visto que possuem um conceito atrelado à questão da temperatura e do turismo, não considerando a questão geomorfológica costeira.

A quase totalidade dos alunos (90\%) compreendem que mudanças climáticas vão além do aumento da temperatura média do ar, o que demonstra o entendimento de que mudança climática não está só atrelada a um fator ambiental, que é algo mais complexo (Figura 4). Os alunos apontaram que mudanças climáticas podem se configurar como alterações na precipitação, como secas na Amazônia ou enchentes em São Paulo. Ainda, questionaram sobre as possíveis mudanças que poderiam ser observadas em suas cidades. Isso mostra que os alunos conseguem transpor o conhecimento acadêmico para seu cotidiano. 


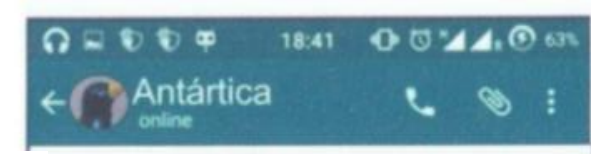

A

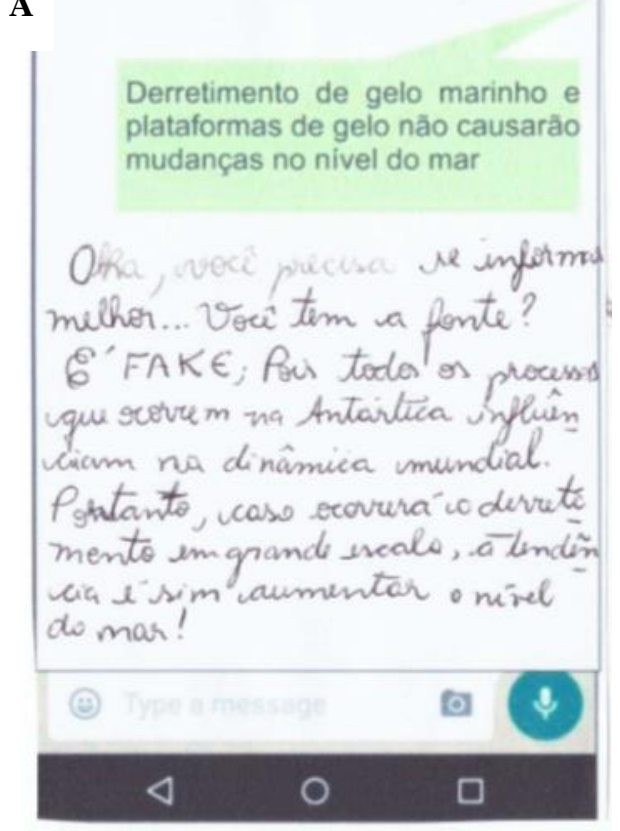

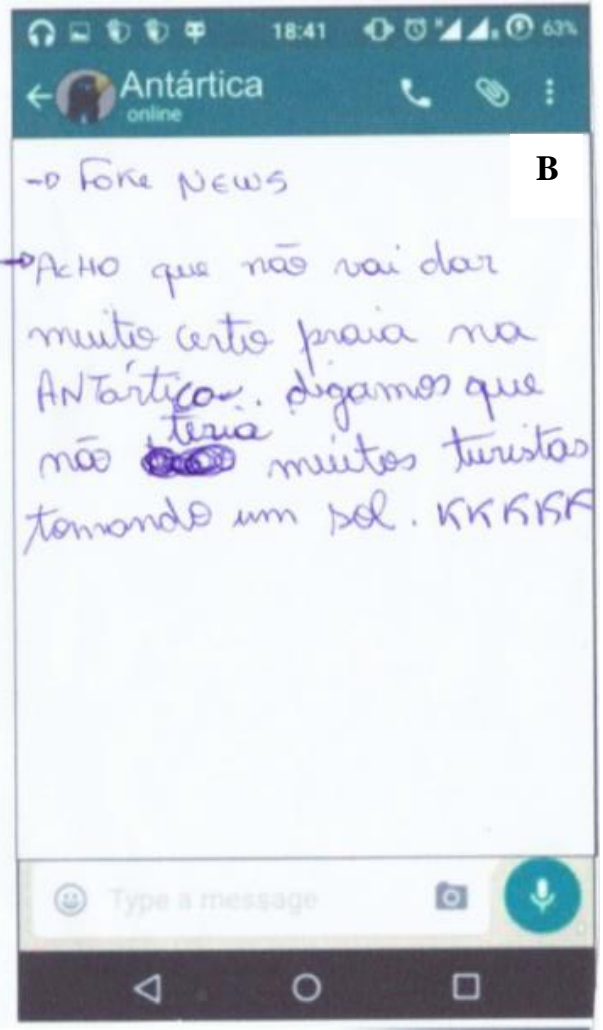

Figura 4. A - Demonstra conhecimento sistêmico quanto às mudanças climáticas, ao considerar que os efeitos são globais; B - Aluno confunde o conceito de praia, apresentando um argumento voltado para questões turísticas ao invés de geomorfológico. Fonte: acervo dos autores, 2019.

Os alunos, na sua maioria (60\%), apontaram que é fundamental preservar o continente, e que mudanças na cadeia alimentar antártica podem ter efeitos no ecossistema local, evidenciando a importância do estudo antártico e a preservação desse ambiente. Também ressaltaram que muitos animais, como baleias, migram para outras regiões, afetando ecossistemas distantes. Muitos alunos lembraram-se do filme Happy Feet 2, em que o Krill é um dos personagens principais, importante crustáceo da base da cadeia alimentar dos mares que cercam a Antártica.

Sobre a percepção de que na Antártica sempre é muito frio, os alunos apresentaram conhecimento plausível quanto às estações do ano e climatologia, sendo que $75 \%$ disseram que é possível haver uma grande amplitude térmica no continente, visto que é uma massa de gelo grande e que as estações do ano, assim como mudam a temperatura no Brasil, afetam a Antártica. Alguns alunos (aproximadamente 10\%) ainda citaram que pode haver influência do mar e continentalidade na temperatura do Antártica. Dessa forma, julgaram que próximo ao mar poderia haver temperaturas mais amenas, do que no interior do continente. A informação apresentada no WhatsApp foi que 
poderia haver uma amplitude entre $-89^{\circ} \mathrm{C}$ e $+17^{\circ} \mathrm{C}$, sendo respectivamente a menor e a maior temperatura já registradas na Antártica ${ }^{1}$.

Cerca de metade dos alunos (40\%) citaram que, nas disciplinas de Geotecnologias e Sensoriamento Remoto, aprenderam sobre sensores e satélites. Dessa forma, a maioria apontou que é possível ter sinal de celular e internet na Antártica (Figura 5A). Apesar de ser somente uma curiosidade, também demonstra a aplicação do conhecimento de outra disciplina dentro do ensino de regiões polares.

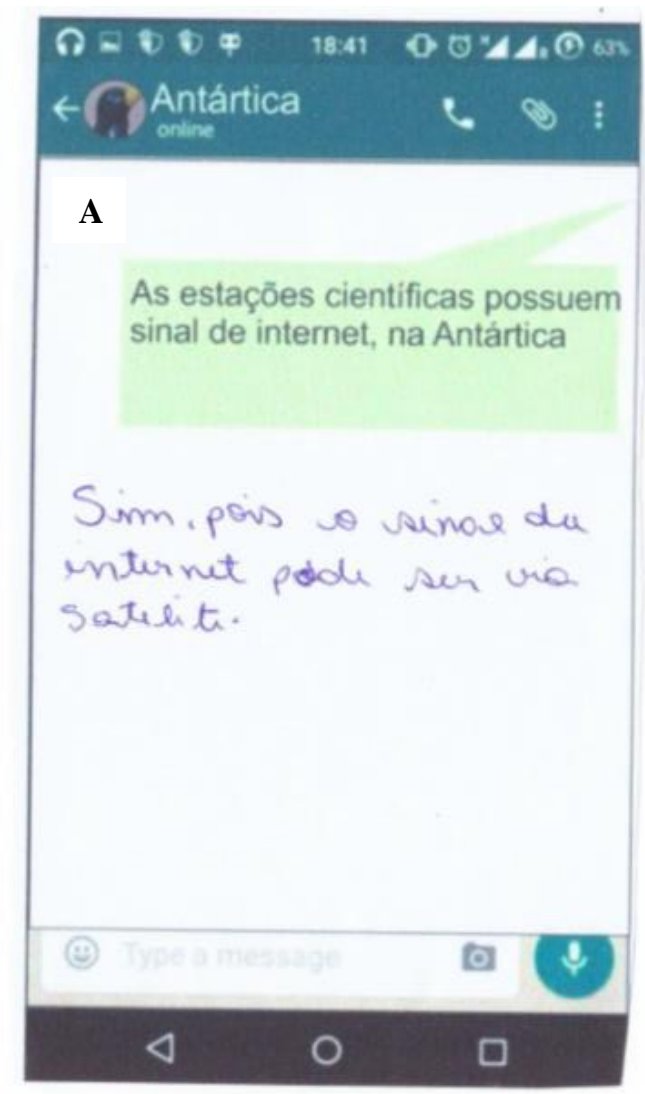

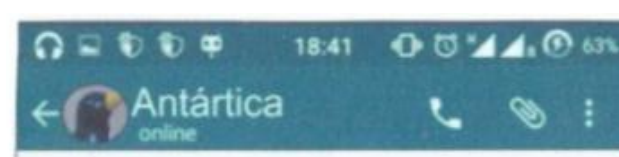

B

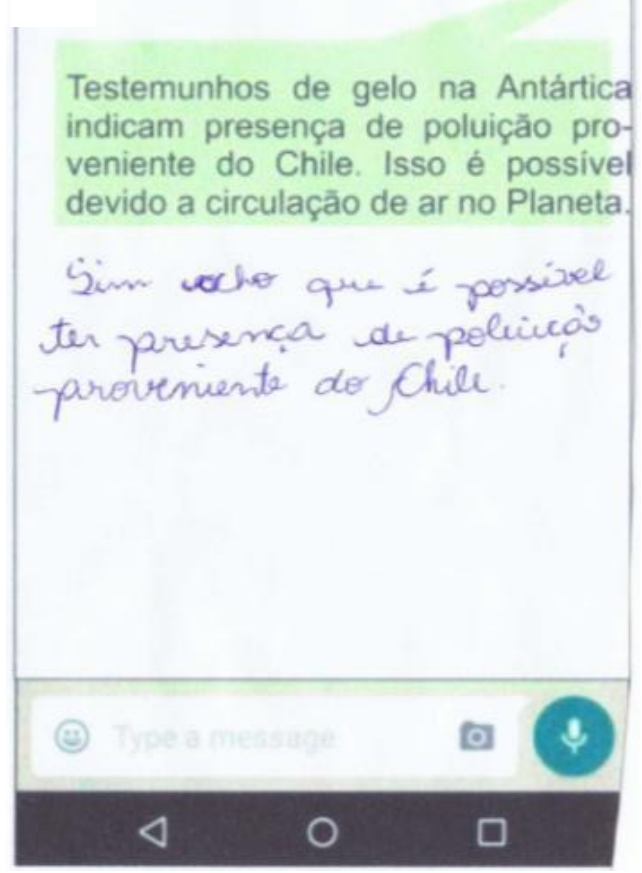

Figura 5: A - Aluno demonstra conhecimento sobre a disciplina de Sensoriamento Remoto em relação à comunicação no continente; B - Aluno mostra entendimento sobre circulação atmosférica ao afirmar que é possível ter poluição de mineradora chilena no continente antártico. Fonte: acervo dos autores, 2019.

Ainda analisando a Figura 5, nota-se o que os alunos têm a percepção de que a poluição pode chegar na Antártica. Na sua maioria (65\%), os discentes acreditam que a poluição produzida em

\footnotetext{
${ }^{1}$ A temperatura máxima, mencionada no texto, era o maior registro de temperatura na época em que a oficina foi realizada.
} No ano de 2020, nova temperatura máxima foi registrada em diversas estações meteorológicas da Antártica marítima. 
mineradoras no Chile pode atingir a Antártica (Figura 5B), devido à circulação atmosférica. Novamente, demonstraram conhecimento da disciplina de Climatologia.

A partir da compilação das análises das respostas e discussões da oficina, uma tabela foi construída (Tabela 2) onde são apresentadas algumas disciplinas do currículo da graduação em Geografia que são pertinentes para abordagem de mudanças climáticas e Antártica. As disciplinas selecionadas foram: Análise de paisagem, Climatologia, Biogeografia, Geomorfologia, Cartografia, Geografia Cultural e Geografia da População. São apresentados, também, temas e possíveis discussões interdisciplinares.

Tabela 2. Disciplinas em que pode ser trabalhado o conceito e impactos das Mudanças Climáticas, considerando a temática humana e física da Geografia.

\begin{tabular}{|c|c|c|}
\hline $\begin{array}{c}\text { Disciplinas e tópico } \\
\text { temático }\end{array}$ & Objetivo & $\begin{array}{l}\text { Como abordar as mudanças climáticas na } \\
\text { disciplina? }\end{array}$ \\
\hline $\begin{array}{l}\text { Biogeografia } \\
\text { Tema 1: fauna e flora }\end{array}$ & $\begin{array}{l}\text { Abordar que mudanças na base } \\
\text { da cadeia alimentar irão causar } \\
\text { alterações ambientais a nível } \\
\text { local e mundial. }\end{array}$ & $\begin{array}{l}\text { Relacionando o aumento/diminuição da } \\
\text { temperatura média do ar e da precipitação na } \\
\text { distribuição da vegetação num critério } \\
\text { latitudinal. }\end{array}$ \\
\hline $\begin{array}{l}\text { Geografia da população } \\
\text { e/ou Geografia cultural } \\
\text { Tema 1: migração }\end{array}$ & $\begin{array}{l}\text { Abordar as principais relações } \\
\text { entre a população e as } \\
\text { mudanças climáticas e } \\
\text { impactos } \\
\text { associados. }\end{array}$ & $\begin{array}{l}\text { Apresentando os povos tradicionais do Ártico, } \\
\text { por exemplo, a questão cultural do povo Inuit e } \\
\text { sua migração forçada pelas mudanças de } \\
\text { temperatura. A migração de outros povos, } \\
\text { forçada pelas mudanças ambientais e escassez } \\
\text { de recursos (refugiados climáticos) é outro } \\
\text { assunto que pode ser utilizado. Mostrar a } \\
\text { questão cultural, sobre a perda do lugar dos } \\
\text { povos refugiados e as implicações desses } \\
\text { fenômenos migratórios nas identidades é, } \\
\text { também, uma estratégia para essa(s) } \\
\text { disciplina(s). }\end{array}$ \\
\hline $\begin{array}{l}\text { Geografia agrária } \\
\text { Tema 1: êxodo rural; } \\
\text { Tema 2: agricultura } \\
\text { familiar }\end{array}$ & $\begin{array}{l}\text { Relacionar aspectos das } \\
\text { mudanças climáticas e seus } \\
\text { impactos na população rural e } \\
\text { na possibilidade de culturas } \\
\text { ampliarem sua } \\
\text { agroclimática. }\end{array}$ & $\begin{array}{l}\text { Apresentação das novas condições de } \\
\text { temperatura e de precipitação, que farão com } \\
\text { que diferentes culturas tenham possibilidade de } \\
\text { se desenvolver em outras latitudes, } \\
\text { transformando toda agricultura e a pecuária. } \\
\text { Discussão sobre a atuação das mudanças } \\
\text { climáticas no êxodo rural. }\end{array}$ \\
\hline
\end{tabular}




\begin{tabular}{|c|c|c|}
\hline & & $\begin{array}{l}\text { Avaliar o impacto das mudanças climáticas na } \\
\text { agricultura familiar. }\end{array}$ \\
\hline $\begin{array}{l}\text { Climatologia } \\
\text { Tema 1: circulação do ar } \\
\text { e albedo } \\
\text { Tema 2: qualidade de } \\
\text { vida da população }\end{array}$ & 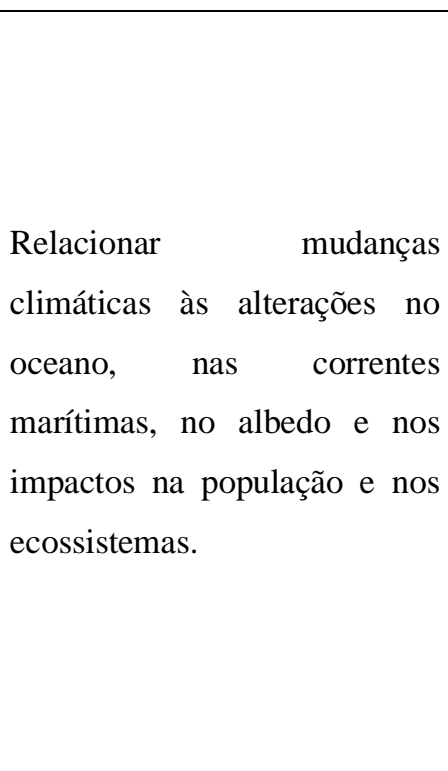 & $\begin{array}{l}\text { Debate sobre mudanças na circulação do ar } \\
\text { decorrente de mudanças de temperatura média } \\
\text { do ar no globo terrestre. } \\
\text { Demonstrar que as mudanças causadas pela } \\
\text { diminuição do gelo marinho do Ártico alteram } \\
\text { o albedo numa área onde o oceano passa a } \\
\text { receber maior quantidade de energia, } \\
\text { provocando seu aquecimento. } \\
\text { Quanto à população, pode-se discutir a questão } \\
\text { do conforto térmico e o aumento de doenças } \\
\text { associadas às mudanças climáticas, como as } \\
\text { respiratórias e as disseminadas por mosquitos } \\
\text { vetores. }\end{array}$ \\
\hline $\begin{array}{l}\text { Cartografia } \\
\text { Tema 1: projeções }\end{array}$ & $\begin{array}{l}\text { Trabalhar com a cartografia } \\
\text { polar no que tange sua } \\
\text { localização e implicações nas } \\
\text { projeções cartográficas. }\end{array}$ & $\begin{array}{l}\text { Dúvidas como "A Antártica ou o Ártico fica em } \\
\text { baixo?" São recorrentes e podem ser } \\
\text { trabalhadas em diferentes projeções, para que o } \\
\text { aluno possa ter uma melhor "alfabetização } \\
\text { cartográfica polar" o que será fundamental na } \\
\text { formação geográfica do aluno. É importante } \\
\text { abordar princípios geodésicos e sua influência } \\
\text { nas interpretações dos dados de mudanças } \\
\text { climáticas. }\end{array}$ \\
\hline $\begin{array}{l}\text { Geografia Física } \\
\text { Tema 1: estações do ano } \\
\text { Tema 2: correntes } \\
\text { oceânicas }\end{array}$ & $\begin{array}{l}\text { Abordar a questão do aumento } \\
\text { da temperatura de superfície do } \\
\text { mar. }\end{array}$ & $\begin{array}{l}\text { A importância da distribuição de energia entre } \\
\text { os hemisférios Norte e Sul e a sazonalidade de } \\
\text { fenômenos extremos, bem como a alteração de } \\
\text { seus períodos de ocorrência. } \\
\text { Entender quais são as implicações diretas das } \\
\text { mudanças climáticas no ecossistema antártico e } \\
\text { quais seriam as mudanças a nível global. É } \\
\text { importante discutir os fenômenos de } \\
\text { ressurgência que ocorrem no Pacífico. }\end{array}$ \\
\hline $\begin{array}{l}\text { Geomorfologia } \\
\text { Tema 1: relevo }\end{array}$ & $\begin{array}{l}\text { Explicar aos alunos que as } \\
\text { mudanças } \\
\text { transformarão a plimáticas } \\
\text { glacial, na Antártica, e em } \\
\text { áreas de risco, no Brasil. }\end{array}$ & $\begin{array}{l}\text { Explanação sobre a dinâmica da paisagem } \\
\text { glacial e como o aquecimento global pode } \\
\text { alterar paisagens na Antártica e em zonas } \\
\text { costeiras. Também podem ser apresentados } \\
\text { exemplos em que morainas, em regiões andinas, }\end{array}$ \\
\hline
\end{tabular}




\begin{tabular}{l|l|l}
\hline & podem represar água de derretimento glacial e \\
& como sua ruptura modifica o ambiente e causa \\
mortes. & \\
No Brasil, é possível discutir sobre as áreas de \\
riscos à inundação e os movimentos de massa \\
bem como suas relações com o aumento de \\
eventos extremos e a intensificação de \\
desastres.
\end{tabular}

Fonte: elaborado pelos autores, 2019.

\section{DISCUSSÕES}

De maneira geral, verificou-se que o uso do WhatsApp permitiu uma maior interação e curiosidade dos alunos para com "Mudanças climáticas e Antártica", visto que muitos alunos relataram que frequentemente recebem informações fake sobre o tema através desse aplicativo. As novas abordagens envolvendo o WhatsApp foram apresentadas para os licenciandos em Geografia, em um momento que muitos deles já estão fazendo o estágio docência nas escolas, e a animação com a oficina se refletiu na fala de alguns que relataram que iriam adaptar a atividade com os alunos do ensino fundamental e médio.

Ainda, recomendamos que outras mídias sejam consideradas como ferramentas potenciais para o ensino de Mudanças Climáticas e Antártica, visando contribuir para as discussões sobre a Geografia escolar envolvendo essa temática. O Youtube, por exemplo, que hoje é utilizado para visualização de vlogs feitos por youtubers, possui também relatos de viagens até a Antártica. Esse material pode abrir possibilidades pedagógicas no ensino do continente, ao transmitir informações e experiências de youtubers admirados pelos alunos, e proporcionar debates em sala de aula. O Instagram também pode ser utilizado nessa estrutura de oficina, pois possui uma série de perfis de fotógrafos que viajam o mundo registrando alterações nos ambientes e impactos na sociedade, decorrente de mudanças climáticas.

De forma geral, contribui-se para explorar as potencialidades das tecnologias, como o Whats App, que envolvem as redes sociais on-line no processo de ensino-aprendizagem. Assim como destaca Santos et al. (2015), ressaltamos que a diversidade de plataformas virtuais que podem ser trabalhadas em sala de aula pode ser importante para o ensino, mas o professor possui um papel 
fundamental no modo em que as diversas informações disponíveis nestas plataformas chegarão aos alunos e se estas terão relevância no processo de ensino-aprendizagem de conceitos de Geografia.

Com a aplicação das atividades observa-se que os alunos começaram a imaginar e à explorar o novo ambiente. Santos et al. (2015) afirma que o uso das mídias virtuais no processo de ensinoaprendizagem, explica-se pelo fato de que estas ferramentas exercem uma grande influência no imaginário dos alunos, estimulando a sua capacidade interpretativa.

Contudo, mesmo que os resultados dessa oficina tenham sido satisfatórios, o assunto "ensino de mudanças climáticas" ainda demanda muitas discussões e reflexões metodológicas para potencializar o aprendizado do aluno diante de toda complexidade desse tema. Jacobi et al. (2011) ressalta que o maior desafio no ensino de mudanças climáticas é realizar um aprofundamento científico sobre o tema dentro da educação, com a elaboração de material interdisciplinar. No entanto, no currículo da graduação em Geografia, geralmente tem-se o conteúdo programático de mudanças climáticas associado à(s) disciplina(s) de Climatologia, o que torna os debates somente focados e resumidos aos aspectos climáticos, menosprezando questões atreladas ao homem (geopolítica e cultura) e ao meio (causas e efeitos desses processos de forma holística). No entanto, ao abordar as notícias relativas às mudanças do clima, notou-se ser fundamental a apresentação do conceito de Geossistema. Morais (2013) afirma que a teoria geossistêmica rompe com a compartimentação existente na geografia física, e possibilita, ao aluno, a compreensão da realidade da qual eles fazem parte e permite a reflexão das temáticas físico-naturais do espaço geográfico.

Conforme identificado nos resultados, os alunos conseguiram realizar um pensamento de causa e efeito dentro de uma perspectiva sistêmica, uma vez que concebem que uma alteração na Antártica pode alterar o nível médio dos mares (Figura 5A) ou que um poluente pode se deslocar pela atmosfera e depositar-se em outro continente (Figura 5B). Assim, a divulgação de pesquisas brasileiras, como a de Schwanck et al. (2017) - que apontam que partículas provenientes de mineração chilena atingem o continente antártico - são bons exemplos para serem utilizados em sala de aula, já que demonstram, com metodologia científica, como atua a circulação atmosférica e como uma ação realizada em uma parte do globo pode causar mudanças ambientais em outra região.

Analisando as disciplinas elencadas na Tabela 2, percebe-se que a abordagem das mudanças climáticas nas disciplinas de biogeografia, geografia da população, geografia agrária, geografia cultural, climatologia, cartografia, geomorfologia e geografia urbana, aprofundando essas relações sistêmicas entre o físico e o humano, permitem abordar o contexto social dessas transformações. É possível evidenciar qual a capacidade da população para adaptar-se a essas novas condições, passando 
por assuntos como: possíveis migrações, em função do aumento de eventos extremos; mudanças na flora e fauna, com adaptação dos animais e plantas, mudando a espacialização destes ecossistemas; mudanças em determinadas culturas, que poderão passar a ocupar outras áreas com latitudes diferentes; e mudanças no nível do mar, nas correntes marítimas, na erosão e nos movimentos de massa. Por fim, os aspectos cartográficos vão colaborar com a interpretação espacial dos eventos e a compreensão das relações entre as diferentes porções da Terra.

De maneira geral, recomenda-se que todas as disciplinas acima mencionadas adotem estratégias de ensino-aprendizagem ativas, envolvendo situações como, por exemplo: o mapeamento e análise de dados estimulando os alunos a produzirem produtos cartográficos que evidenciam as mudanças climáticas; buscar artigos em plataformas científicas e promover debates em aula; acessar notícias, em tempo real, e estabelecer conexões entre eventos que ocorrem no Brasil com situações em outros países; e analisar informações divulgadas pelo IPCC (Painel Intergovernamental sobre Mudanças Climáticas).

Ressalta-se a importância de não se utilizar somente exemplos de outros países, criando um cenário de mudanças climáticas que não pode ser visto no cotidiano do aluno. É necessário criar uma discussão sobre mudanças climáticas tendo o Brasil como palco, vislumbrando as facetas dessas transformações nas cidades em que os alunos moram. Cabe, ao professor, estimular essa discussão e formar futuros geógrafos com conhecimento local e global, e que possam agir como planejadores e educadores que saibam aproximar temas cotidianos dos conceitos geográficos.

Por fim, sobre o papel do professor (ou ministrante), destacamos que este deve estar preparado para discutir a pauta "mudanças climáticas e Antártica", propondo reflexão e crítica aos materiais utilizando conhecimento científico para tanto. Somente apresentar dados sem que haja síntese, análise e correlação entre as disciplinas e diferentes áreas da Terra, não contribui para um ensino efetivo do tema. Contudo, as barreiras e desafios para que isso se construa são grandes: ainda é escasso o material em português sobre este assunto; o livro didático traz dados desatualizados; o continente antártico fica restrito a uma discussão climatológica sem considerar outras áreas do conhecimento; e a discussão da mudança climática no Brasil precisa chegar à sociedade como um todo.

Os resultados demonstram que há possibilidades para o uso desta tecnologia no ensino das mudanças climáticas e que estas podem enriquecer o cotidiano dos alunos, tornarem as aulas mais dinâmicas e estimular o interesse pela disciplina que utiliza as mídias, assim como trazem Santos et al. (2015). 


\section{CONSIDERAÇÕES FINAIS}

A escolha da estrutura de um aplicativo de mensagem mostrou a importância em utilizar-se a forma de comunicação cotidiana, dos alunos, para dentro da sala de aula. Foi possível perceber que, ao realizar essa atividade, os alunos demonstraram muito interesse em todas as etapas, uma vez que envolve temas e contextos cotidianos, como receber uma mensagem pelo WhatsApp. Isso pode ser evidenciado pela participação da totalidade dos alunos (40) durante toda a execução da oficina. A atividade lúdica, utilizando um aplicativo para smartphone é uma forma de instigar o aluno numa proposta investigativa e desafiadora, permitindo analisar, de forma indireta, o conhecimento crítico e integrado dos discentes ao abordar assuntos como mudanças climáticas e Criosfera, acompanhando seu domínio do conjunto teórico e conceitual da Geografia.

A oficina também estimulou a valorização da formação em Geografia, constituindo uma forma de diminuir as fake news geográficas compartilhadas e destacando o ensino de geografia, visto que os alunos conseguiram apresentar argumentações interdisciplinares, mesmo com conteúdos fragmentados no currículo. Essa proposta demonstra o quanto é importante promover esses espaços na formação dos alunos, propiciando, a eles, que consigam mobilizar os conhecimentos das diversas disciplinas num ensino-aprendizagem sistêmico e integrado. Dessa forma, a atividade envolvendo WhatsApp ao demonstrar a visão sistêmica de muitos alunos, em relação às mudanças climáticas, revelou uma série de possibilidades desse assunto, atrelado não somente à disciplina de Climatologia.

Tendo em vista que as mudanças climáticas envolvem conhecimentos de diversas áreas da Geografia, como Climatologia, Biogeografia, Hidrografia, Geopolítica, Geografia Cultural, entre outras, ressalta-se que se deve pensar a prática pedagógica e docente em uma perspectiva interdisciplinar. Isso ocorre pela necessidade de abordagem de aspectos específicos das subáreas da Geografia Física e da Geografia Humana, bem como de suas interfaces, para contextualizar e analisar situações próprias de um tema que tem consequências diretas em várias esferas terrestres e humanas. As mudanças climáticas podem ser consideradas um novo paradigma no ensino da geografia escolar e superior, necessitando novas metodologias para guiar o professor nessa tarefa. O professor precisa, também, de atualização constante, pois a quantidade e a diversidade de materiais publicados são grandes e é intensa a disseminação de fake news. Então, nesse sentido, é importante que sejam elaborados materiais em língua portuguesa e que sejam de fácil acesso para uso em sala de aula. Por fim, o material criado no formato WhatsApp, nessa oficina, pode ser disponibilizado online, para que mais educadores tenham acesso e possam partir dessas informações para aprimorar suas aulas. 


\section{AGRADECIMENTOS}

À FAPERGS, CAPES, IFRS e INCT da Criosfera.

\section{REFERÊNCIAS}

ALMEIDA, L. M. W. de.; FONTANINI, M. L. de C. Aprendizagem significativa em atividades de modelagem matemática: uma investigação usando mapas conceituais. Investigação em ensino de ciências, v.15, p.403-425, 2010.

BERTOTTI, A. P.; ROSA, K. K.; HOLGADO, F. L. Criosfera e mudanças climáticas: uma abordagem para o ensino fundamental. In: ENCONTRO DE PRÁTICAS DE ENSINO DE GEOGRAFIA DA REGIÃO SUL, $1^{\circ}$., 2013, Porto Alegre. Anais... Porto Alegre: UFRGS. 2013, p. $38-44$

JACOBI, P. R.; GUERRA, A. F. S.; SULAIMAN, S. N.; NEPOMUCENO, T. Mudanças climáticas globais: a resposta da educação. Revista Brasileira de Educação, v. 16 n. 46, 2011.

OLIVEIRA, F.; TONINI, I. M. Geografia e educação on-line: rede social transformada em ambiente virtual de aprendizagem. In: CASTROGIOVANI, A.C.; TONINI, I. M.; KAERCHER, N.A.; COSTELLA, R.Z. (Org). Movimentos do ensinar geografia rompendo rotações. Porto Alegre: Evangraf Ltda. 280p. 2015.

MORAIS, E. M. B. de. As temáticas físico-naturais no ensino de geografia. In: CAVALCANTI, Lana de Souza. Temas da Geografia na escola básica. Campinas, SP: Papirus, 2013.

MORAN, J. M.; MASSETTO, M. T.; BEHRENS M. A. Novas tecnologias e mediações pedagógicas. Campinas, SP. Papirus, 2012.

SANTOS, M. F. P.; PINTO, M.V.; GALDINO, V. H. O facebook no ensino de Geografia: desafios e potencialidades. In: SACRAMENTO, A.C.R; ANTUNES, C.F.; FILHO, M.M.S. Ensino de Geografia: produção do espaço e processos formativos. Rio de Janeiro: Consequência Editora. 398p. 2015.

SCHWANCK, F.; SIMÕES, J. C.; HANDLEY, M.; MAYEWSKI, P. A.; BERNARDO, R. T.; AQUINO, F. E. Drilling, processing and first results for Mount Johns ice core in West Antarctica Ice Sheet. Brazilian Journal of Geology, São Paulo, v. 46, n. 1, p. 29-40, 2016.

STÜRMER, A. B. As TIC'S nas escolas e os desafios no ensino de geografia na educação básica. Geosaberes, Fortaleza, v. 2, n. 4, p. 3-12, 2011.

TONETTO, E.P.; TONINI, I. M. Redes sociais e práticas escolares: plataformas para a construção de uma Geografia on-line. In: CASTROGIOVANI, A.C.; TONINI, I.M.; KAERCHER, N.A.; 
Revista Ensino de Geografia (Recife) V. 3, No. 2, 2020

DOI: https://doi.org/10.38187/regeo2020.v3n2id242956

COSTELLA, R.Z. (Org). Movimentos do ensinar geografia rompendo rotações. Porto Alegre: Evangraf Ltda. 280p. 2015. 